\title{
PENGARUH KUALITAS PRODUK, DAN PELAYANAN PRIMA TERHADAP KEPUASAN PELANGGAN: STUDI KASUS LABORATORIUM KLINIK PRODIA CABANG KRAMAT
}

\author{
Dwi Listyowati ${ }^{1}$, Eva Fadilah ${ }^{2}$, Rachmawaty Haroen3, Johan Hursepuny4 \\ Sekolah Tinggi Ilmu Ekonomi Jayakarta \\ dwilistyowati6@gmail.com¹, evafadillah26@gmail.com², \\ rachmawatyharoen@gmail.com ${ }^{3}$,johnhur59@gmail.com ${ }^{4}$
}

\begin{abstract}
ABSTRAK
Penelitian ini bertujuan untuk menganalisis pengaruh kualitas produk dan pelayanan prima terhadap kepuasan pelanggan di Laboratorium Klinik Prodia Cabang Kramat. penelitian ini dilakukan pada pelanggan yang akan melakukan tes pemeriksaan kesehatan pada cabang kramat. Jenis penelitian yang digunakan adalah jenis penelitian kuantitatif. Teknik Pengumpulan data penelitian menggunakan metode kuesioner. Selanjutnya, teknik pengambilan sampel yang digunakan adalah Purposive Sampling dengan jumlah responden seratus orang. Hasil pengujian dan analisisnya menunjukkan bahwa $\mathrm{F}$ hitung $>\mathrm{F}$ tabel atau 72,546 > 3,09 dan nilai signifikasi < 0,05 atau $0,00<0,05$ maka terdapat pengaruh kualitas produk dan pelayanan prima secara simultan sangat signifikan terhadap kepuasan pelanggan. Hal ini dibuktikan dengan nilai koefisien determinasi (KD) sebesar 0,599 atau 59,90\%, berarti sebesar 59,90\% kontribusi atau pengaruh variabel Kualitas Produk $\left(\mathrm{X}_{1}\right)$ dan Pelayanan Prima $\left(\mathrm{X}_{2}\right)$ secara simultan (bersama-sama) terhadap variabel Kepuasan Pelanggan (Y), sedangkan sisanya sebesar 40,10\% adalah pengaruh faktor lainnya yang tidak diteliti. Saran untuk perusahaan kedepannya lebih meningkatkan Pelayanan Prima dari segi akses yaitu mengadakan pelatihan untuk customer service, memaksimalkan jadwal kerja shift sesuai trafic call, fasilitas kebutuhan customer service dengan teknologi terbaru, mengurangi waktu menunggu di setiap panggilan.
\end{abstract}

Kata Kunci: Kualitas Produk, Pelayanan Prima, dan Kepuasan Pelanggan

\begin{abstract}
This study aims to analyze the effect of product quality and excellent service on customer satisfaction at the Prodia Clinics Laboratory Branch of Kramat. This research was held on customers who conduct medical check up on kramat branch with quantitative research type. Questionnaire method was wed as the data collection method furthermore, purposive sampling was used as the sampling technique with a hundred people of respodent number.The test results and analysis show that $F$ count $>F$ table or $72.546>3.09$ with significance value $<0.05$ or 0.00 $<0.05$. Thus, there is a significant influence of product quality and excellent service simultaneously on customer satisfaction. It was proved by the coefficient of determination (KD) of 0.599 or $59.90 \%$, which means $59.90 \%$ of contribution or the affect of Product Quality variable (X1) and Excellent Service (X2) simultaneously (together) affecting the variable Customer Satisfaction $(Y)$, while the remaining $40.10 \%$ is the not-examined factor.Suggestions for the company in the future to further improve Service Excellence in terms of access is to hold training for customer service, arrange shift work schedules according to traffic calls, facilities for customer service needs with the latest technology, reduce waiting time on each call.
\end{abstract}

Keywords: Product Quality, Excellent Service, and Customer Satisfaction. 


\section{PENDAHULUAN}

Kesehatan merupakan salah satu kebutuhan hidup yang sangat penting dalam menunjang aktifitas sehari-hari. Kebutuhan terhadap produk dan layanan kesehatan menjadi prioritas utama. Setiap individu akan berusaha mencapai status kesehatan dengan menginvestasikan dan atau mengonsumsi sejumlah barang dan jasa kesehatan. Status kesehatan yang baik tersebut dibutuhkan sarana kesehatan yang baik pula.

Masyarakat maupun perusahaan menjadi semakin selektif untuk memenuhi kebutuhan jasmani dan rohaninya, untuk mendapatkan produk dan layanan yang sesuai dengan keinginan mereka. Kualitas produk yang di berikan kepada pelanggan dan layanan prima atau service excellent menjadi salah satu yang berpengaruh terhadap kepuasan pelanggan. Kepuasaan pelanggan menjadi faktor penting dalam sebuah bisnis di bidang laboratorium klinik untuk meraih kesuksesan.

Laboratorium Klinik adalah suatu lembaga yang bergerak di bidang jasa/pelayanan kesehatan. Sesuai dengan peraturan Menteri Kesehatan Republik Indonesia nomor 411/MENKES/PER/III/2010 tentang Laboratorium Klinik. Saat ini laboratorium klinik menghadapi berbagai tantangan untuk dapat melaksanakan fungsinya untuk memberikan pelayanan kesehatan, salah satunya adalah PT Prodia Widahusada Tbk.

PT Prodia Widahusada Tbk atau yang dikenal dengan Laboratorium Klinik Prodia merupakan perusahaan pemeriksaan Laboratorium Klinik terkemuka di Indonesia. Prodia merupakan jejaring laboratorium klinik swasta terbesar berdasarkan besarnya jejaring dan pendapatannya di Indonesia. Prodia fokus menyediakan pemeriksaan diagnostik berkualitas dan layanan prima serta pemeriksaan kesehatan lainnya.

Layanan prima sangat diterapkan oleh laboratorium klinik Prodia, Prodia sendiri mempunyai slogan 3STIPC (senyum, sapa, salam, ucapkan terima kasih tulus ikhlas penuh cinta), slogan tersebut harus diterapkan oleh setiap divisi pelayanan, sehingga pelanggan dapat merasakan pelayanan yang prima.

Pelayanan prima dapat mencapai tujuannya dengan beberapa syarat yang harus dipenuhi. Syarat yang harus dipenuhi adalah tersedia, dapat diterima, efisien dan bermutu. Tersedianya tenaga medis dengan keahlian dan keterampilan yang menjadi unsur paling penting bagi pelanggan dalam memilih penyediaan jasa kesehatan yang tepat.

Nilai dari pelayanan prima suatu laboratorium klinik adalah pelanggan yang menggunakan jasa laboratorium klinik tersebut. Faktor yang mempengaruhi kepuasan pelanggan adalah kepercayaan pelanggan terhadap perusahaan. Kinerja yang baik akan menimbulkan kepercayaan pelanggan, yang selanjutnya akan menciptakan kepuasan pelanggan.

\section{KAJIAN LITERATUR}

Pemasaran berhubungan dengan mengidentifikasi dan memenuhi kebutuhan manusia dan masyarakat. Salah satu dari definisi pemasaran terpendek adalah "memenuhi kebutuhan secara menguntungkan". Pemasaran yang baik bukan kebetulan, merupakan seni dan sains, dan hasil dari perencanaan dan pelaksaan yang cermat menggunakan alat dan teknik canggih. Peter Drucker (Philip Kotler, 2013:6) seorang ahli teori manajemen terkemuka, mengatakan sebagai berikut Orang dapat mengasumsikan akan selalu ada kebutuhan penjualan. Akan tetapi, tujuan pemasaran bukan untuk memperluas pejualan hinga ke mana-mana. Tujuan pemasaran adalah mengetahui dan 
memahami pelanggan sedemikian rupa sehingga produk dan jasa itu cocok dengan pelanggan dan selanjutnya menjual dirinya sendiri. Idealnya, pemasaran hendaknya menghasilkan seseorang pelanggan yang siap untuk membeli. Semua yang dibutuhkan selanjutnya adalah menyediakan produk atau jasa itu.

Menurut Philip Kotler (Sunyoto, 2012: 218), "Pemasaran adalah suatu proses sosial dan manajerial dimana individu dan kelompok memperoleh apa yang mereka butuhkan dan inginkan melalui penciptaan dan pertukaran produk serta nilai dengan pihak lain." Menurut William J. Stanton (Mulyadi Nitisusantro, 2013: 108) Pemasaran adalah suatu sistem keseluruhan dari kegiatan-kegiatan bisnis yang ditujukan untuk merencanakan, menentukan harga, mempromosikan, dan mendistribusikan barang dan jasa yang memuaskan kebutuhan baik kepada pembeli yang ada maupun pembeli potensial. Perkembangan pendekatan dalam manajemen pemasaran dilandasi oleh konsep yang merupakan dasar dari pemimpin perusahaan atau organisasi lainnya dalam menjalankan kebijakan dan strategi pemasaran yang akan dilakukannya. Hal ini karena manajemen pemasaran merupakan usahausaha yang dilakukan untuk mencapai hasil yang diinginkan pada pasar yang dituju (sasaran). Dalam pelaksanaannya sering terjadi pertentangan kepentingan. Oleh karena itu, kegiatan pemasaran harus dijalankan atas dasar falsafah pemikiran dari pemasaran yang bertanggung jawab.

Setiap perusahaan selalu berusaha untuk tetap hidup, berkembang dan mampu bersaing. Salah satu unsur dalam strategi pemasaran terpadu adalah bauran pemasaran, yang merupakan strategi yang dijalankan perusahaan, yang berkaitan dengan penentuan bagaimana perusahaan menyajikan penawaran produk pada segment pasar tertentu, yang merupakan sasaran pasarnya.

. Menurut Rambat Lupiyoadi (2013: 92), Bauran pemasaran merupakan perangkat/alat bagi pemasar yang terdiri atas bebagai unsur suatu program pemasaran yang perlu dipertimbangkan agar implementasi strategi pemasaran dan penetuan posisi yangditetapkan dapat berjalan sukses.

Menurut Philip Kotler (2013: 17), pengertian bauran pemasaran dalah seperangkat alat pemasaran yang digunakan perusahaan untuk terusmenerus mencapai tujuan pemasarannya di pasar sasaran.

Strategi Pemasara Menggunakan Bauran Pemasaran Unsur 4p yaitu produk (product), harga (price), lokasi (place), dan promosi (promotion). Para pemasar pada umumnya menggunakan bauran pemasaran ini sebagai alat untuk mendapatkan tanggapan yang diinginkan oleh perusahaan dari pasaran mereka atas produk yang ditawarkan oleh perusahaan untuk menciptakan pembelian. Dapat disimpulkan bahwa bauran pemasaran mempengaruhi keputusan pembelian konsumen.

Produk menurut Charles W. Lamb (2012: 414), Produk didefinisikan sebagai segala sesuatu baik yang menguntungkan maupun tidak yang diperolah seseorang melalui pertukaran. Menurut Nana $\mathrm{H}$. Abdurrahman (2015: 71), "Produk dalam pengertian umum adalah segala sesuatu yang dapat ditawarkan ke pasar untuk mendapatkan perhatian, dibeli, dipergunakan atau dikonsumsi dan dapat memuaskan keinginan dan kebutuhan."

Penggolongan produk menurut Philip Kotler (Ancellawati, 2013: 215-218) dibagi menjadi klasifikasi barang konsumen dan barang industri. Menurut Kotler dan Armstrong (2012: 272), keputusan yang berhubungan dengan pengembangan dan pemasaran produk 
individual terdiri dari: atribut produk, penetapan merek, kemasan dan pelabelan.

Definisi harga menurut Fandy Tjiptono (2014:151) menyatakan harga

yang ditukarkan agar memperoleh hak kepemilikan atau penggunaan suatu barang atau jasa.

Tempat/Lokasi Pelayanan menurut Ratih Hurriyati (2011: 55) untuk produk industri manufaktur place diartikan sebagai saluran distribusi, sedangkan untuk produk industri jasa, place diartikan sebagai tempat pelayanan jasa. Jadi, saluran distribusi itu sendiri.

Menurut Rambat Lupiyoadi (2013 :42), Lokasi berhubungan dengan di tempat perusahaan harus bermarkas dan melakukan operasi atau kegiatan. Lokasi merupakan salah satu faktor terpenting yang mempengaruhi perkembangan suatu bisnis. Lokasi yang strategis akan mendatangkan banyak konsumen sehingga mampu menaikkan penjualan.

Menurut Suryana (2013: 218), Kegiatan-kegiatan tersebut dapat dilakukan dengan periklanan dan promosi. Oleh karena itu, promosi merupakan cara mengomunikasikan barang-barang dan jasa yang akan ditawarkan supaya konsumen mengenal dan membeli, sesuai dengan fungsi promosi yaitu menginformasikan, membujuk, mengingatkan, dan memengaruhi, maka melalui promosi barang dan jasa yang dihasilkan akan mudah dikenal oleh konsumen.

Kualitas produk menurut Goetsch (Yamit, 2013: 8) "Kondisi dinamis yang berhubungan dengan produk, jasa, sumber daya manusia, proses, dan lingkungan yang memenuhi atau melebihi harapan.

Kualitas produk menurut Kotler dan Armstrong (2013: 272) Salah satu sarana positioning utama pemasar. Kualitas mempunyai dampak langsung pada kinerja produk atau jasa. Oleh karen itu, kualitas berhubungan erat dengan nilai merupakan satuan moneter atau ukuran lainnya (termasuk barang dan jasa lainnya)

dan kepuasan pelanggan. Menurut Mullins J.W., Orville, Larreche, dan Boyd (2014:422) Apabila perusahaan ingin mempertahankan keunggulan kompetitifnya dalam pasar, perusahaan harus mengerti aspek dimensi apa saja yang digunakan oleh konsumen untuk membedakan produk yang dijual perusahaan tersebut dengan produk pesaing.

Menurut Melayu S. P. Hasibuan (2014:152), Pelayanan adalah bagian dari pemasaran." Pelayanan atau sevice adalah setiap kegiatan atau manfaat yang dapat diberikan suatu pihak kepada pihak lainnya yang pada dasarnya tidak berwujud dan tidak pula berakibat pemilikan sesuatu dan produksinya dapat atau tidak dapat dikaitkan dengan suatu produk fisik. Pelayanan adalah kegiatan pemberian jasa dari suatu produk kepada pihak lainnya.

Menurut M. Nur Rianto Al Arif (2014: 211), Pelayanan disebut sangat baik atau terbaik, akan menjadi prima, manakala dapat atau mampu memuaskan pihak yang dilayani (pelayanan). Menurut Atep Adya Brata (2017: 20), Pelayanan adalah kepedulian kepada pelanggan dengan memberikan layanan terbaik untuk memfasilitasi kemudahan pemenuhan kebutuhan dan mewujudkan kepuasannya, agar mereka selalu loyal kepada organisasi/perusahaan.

Menurut Zaenal Mukarom (2015: 229), Fungsi pelayanan prima melayani pelanggan dengan ramah, tepat, dan cepat memenuhi dan memuaskan masyarakat sesuai dengan kebutuhannya dalam rangka, memberdayakan masyarakat sebagai pelanggan pelayanan publik dan membangun serta menumbuhkan kembali kepercayaan masyarakat terhadap pemerintah. 
Oleh karena itu, pelayanan yang baik dan berkualitas harus tetap dipertahankan dan ditingkatkan dari waktu ke waktu. Menurut Kasmir (2017: 67), Ciri pelayanan yang baik harus diikuti oleh manajemen dalam melayani pelanggan atau nasabah iantaranya yaitu tersedianya karyawan yang baik, sarana prasaran yang baik, samapai dengan mampu memberikan kepercayaan kepada pelanggan.

Menurut Boediwarsono (2015: 7), layanan sepenuh hati adalah layanan yang menggunakan baik hati (perasaan) maupun pikiran (logika)." Konsep dasar dari layanan sepenuh hati adalah dapat memahami perasaan-perasaan diri sendiri tentang siapa sebenarnya kita dan apa yang disumbangkan pada kehidupan profesional dan pribadi.

Kepuasan pelanggan merupakan $\mathrm{H}_{1}$ : Terdapat penilaian terhadap suatu bentuk keistimewahan dari suatu barang atau jasa. Menurut Daryanto (2014: 52), "Kepuasan pelanggan adalah perasaan puas yang didapatkan oleh pelanggan karena mendapatkan value dari pemasok, produsen, dan penyedia jasa."

Menurut Danang Sunyoto (2013: 36), "Harapan pelanggan adalah memegang peranan penting dan sangatH ${ }_{3}$ : Terdapat pengaruh Kualitas Produk dan besar pengaruhnya dalam menentukan kualitas produk dan kepuasan konsumen dalam mengevaluasinya pelanggan akan menggunakan harapannya sebagai standar atau acuan."

Menurut Rambat Lupiyoadi (2013: 158), dalam menentukan kepuasan konsumen terdapat lima dimensi utama yang harus diperhatikan oleh perusahaan, yaitu kualitas produk, kualitas pelayanan, emosioanal harga dan biaya.

Penelitian yang dilakukan oleh Lumintang dan Jopie J (2015) dengan menunjukkan terdapat pengaruh kualitas produk terhadap kepuasan pelanggan. Semakin baik kualitas produk yang diberikan maka akan mempengaruhi tingkat kepuasan konsumen. Sementara itu dalam penelitian Panjta Djati dan Didit Darmawa (2004) menyimpulkan bahwa kualitas layanan berpengaruh signifikan terhadap kepuasan konsumen dan minat mereferensikan.

Berdasarkan teori-teori variabel penelitian, hubungan antar variabel, dan penelitian terdahulu yang difokuskan pada perumusan masalah maka kerangka pemikiran yang akan diterapkan dalam penelitian ini sebagai berikut:

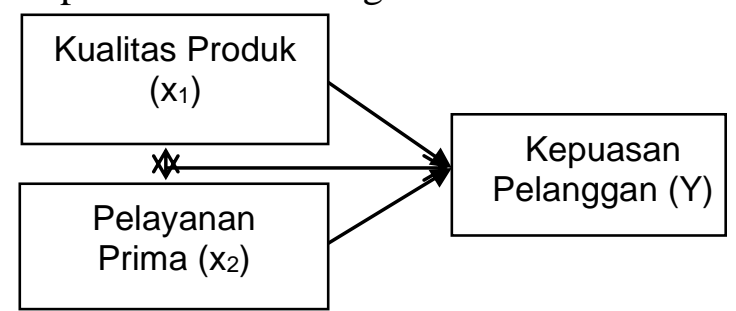

$\begin{array}{ll}\text { pengaruh } & \text { Kualitas } \\ \text { Produk } & \text { terhadap }\end{array}$

Kepuasan Pelanggan pada Laboratorium Klinik Prodia Cabang Kramat.

$\mathrm{H}_{2}$ : Terdapat pengaruh Pelayanan prima terhadap

Kepuasan Pelanggan pada Laboratorium Klinik Prodia Cabang Kramat.

Pelayanan Prima secara simultan terhadap Kepuasan Pelanggan pada Laboratorium Klinik Prodia Cabang Kramat.

\section{III.METODE PENELITIAN}

Penggolongan berdasarkan pemakaiannya, jenis penelitian yang dilakukan adalah jenis penelitian terapan. Penelitian ini dilakukan dengan tujuan agar dapat melakukan sesuatu yang lebih baik, efektif, dan efisien. Dalam penelitian ini dimaksud apakah Kualitas Produk dan Pelayanan Prima Berpengaruh terhadap Kepuasan Pelanggan Laboratorium Klinik Prodia Cabang Kramat. 
Penelitian berdasarkan tujuan penelitian yang digunakan adalah penelitian deskriptif dan eksplanatif yang menggunakan studi kasus pada pelanggan Laboratorium Klinik Prodia Cabang Kramat.

Menurut Sofar Silaen (2018: 16) Penelitian deskriptif bertujuan untuk memberikan deskripsi, gambaran mengenai fakta-fakta, sifat-sifat, serta hubungan antar-fenomena yang diteliti, termasuk hubungan kegiatan-kegiatan, sikap-sikap, pandangan-pandangan, serta proses-proses yang sedang berlansung dan pengaruh-pengaruh dari suatu fenomena, atau untuk menentukan frekuensi distribusi suatu gelaja atau frekuensi adanya hubungan tertentu antara suatu gejala dengan gelaja lain.

Penelitian ini menjelaskan Pengaruh Kualitas Produk dan Pelayanan Prima terhadap Kepuasan Pelanggan studi kasus Laboratorium Klinik Prodia Cabang Kramat. untuk Pengaruh Pelayanan Prima terhadap Kepuasan Pelanggan dalam keputusan pemakaian produk di Laboratorium Klinik Prodia Cabang Kramat, peneliti mengukur dengan data kuesioner yang disebarkan pada pelanggan.

Menurut Sugiono (2017: 61), Definisi Operasional adalah penentuan konstrak atau sifat yag akan dipelajari sehingga menjadi variabel yang dapat diukur.

Variabel bebas (Independent variable) adalah variabel yang menjelaskan atau memengaruhi variabel terikat (Dependent variable). Di dalam penelitian ini variabel independennya adalah kualitas produk dan pelayanan prima. Kualitas produk adalah usaha yang dilakukan oleh perusahaan untuk memenuhi atau bahkan harapan pelanggan. Sedangkan pelayanan prima adalah pelayanan yang sangat baik atau pelayanan yang terbaik yang sesuai dengan standar pelayanan yang berlaku atau dimiliki oleh instansi yang memberikan pelayanan serta memuaskan pelanggan.

Dalam penelitian ini, variabel terikat (dependent variable) yaitu variabel yang tergantung atas variabel lain. Dalam penelitian ini variabel dependennya adalah kepuasan pelanggan, yaitu merupakan penilaian terhadap suatu bentuk keistimewahan dari suatu barang atau jasa..

Teknik pengumpulan data adalah alat penelitian yang digunakan untuk memperoleh informasi yang relefan, akurat dan reliabel. Metode yang digunakan adalah kuesioner. Kuesioner merupakan teknik pengumpulan data yang dilakukan dengan cara memberi seperangkat pertanyaan atau pernyataan tertulis kepada reponden untuk dijawab.

Teknik pengambilan sampel yang digunakan adalah Purposive Sampling, sampel dipilih berdasarkan pertimbangan-pertimbangan tertentu. Pertimbangan tersebut berdasarkan tujuan penelitian, yaitu pelanggan yang datang dan melakukan medical check up di Lab. Klinik Prodia Cabang Kramat.

Adapun teknik analis data yang digunakan adalah dengan melakukan uji asumsi klasik, uji regresi serta uji hipotesis melalui alat bantu program SPSS.

\section{IV.HASIL DAN PEMBAHASAN}

Laboratorium Klinik Prodia adalah Laboratorium Klinik kesehatan yang memiliki jaringan pelayanan prima dan tes pemeriksaan kesehatan lebih dari 2,300 jenis pemeriksaan. Terjaminnya proses dari preanalitik sampai dengan keluar hasil sesuai dengan standarisasi persyaratan Lab. Klinik Prodia yang berlaku di seluruh cabang. 
Jurnal Manajemen dan Bisnis, Volume 2, No. 2, Januari 2021

Di bawah ini diuraikan mengenai data penjualan tes selama 12 bulan tahun 2018 yang dipaparkan dalam tabel, sebagai berikut:

Data Penjualan

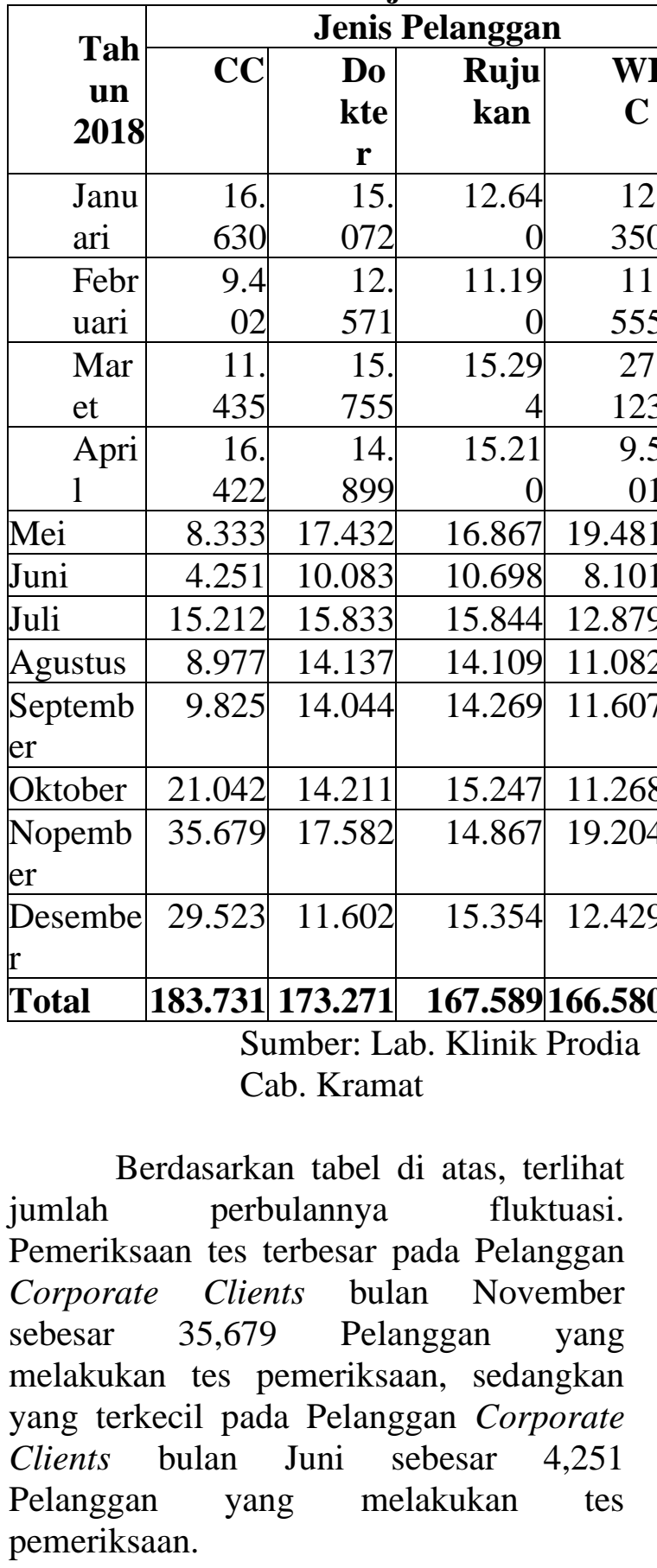

Berdasarkan hasil analisis data, maka didapat hasil perhitungan statistik berdasarkan jenis kelamin subjek penelitian maka diperoleh gambaran sebagai berikut:
Jenis Kelamin Pelanggan

\begin{tabular}{|c|c|c|}
\hline $\mathrm{S}^{\mathrm{Jeni}}$ & $\begin{array}{r}\text { Freq } \\
\text { uency }\end{array}$ & $\begin{array}{c}\text { Pe } \\
\text { rsen }\end{array}$ \\
\hline -laki ${ }^{\text {Laki }}$ & 45 & 45 \\
\hline $\begin{array}{l}\text { Pere } \\
\text { mpuan }\end{array}$ & 55 & 55 \\
\hline I Tota & 100 & $0^{10}$ \\
\hline
\end{tabular}

Pada bagian ini akan digambarkan data primer yang diperoleh dari hasil penyebarluasan kuesioner kepada 100 orang responden. Selanjutnya hasil jawaban dari responden diolah secara statistik deskripsi yang dipaparkan dalam bentuk tabel dan gambar (chart). Pengolahan data dilakukan dengan menggunakan Statistical Product and Service Solutions (SPSS) versi 24.0 dalam tabel atau data lain yang sudah tersedia.

Di bawah ini dipaparkan masingmasing indikator dari dimensi kualitas produk dengan hasil prediksi rata-rata skor.

\section{Dimensi Variabel Kualitas Produk}

\begin{tabular}{|c|l|c|}
\hline No & \multicolumn{1}{|c|}{ Kualitas Produk } & Skor \\
\hline 1 & $\begin{array}{l}\text { Jenis Pemeriksaan di Lab. } \\
\text { Klinik Prodia Lengkap }\end{array}$ & 4,38 \\
\hline 2 & $\begin{array}{l}\text { Jenis Pemeriksaan di Lab. } \\
\text { Klinik Prodia update }\end{array}$ & 4,31 \\
\hline 3 & $\begin{array}{l}\text { Jenis Pemeriksaan di Lab. } \\
\text { Klinik Prodia sesuai dengan } \\
\text { kebutuhan/ riteria }\end{array}$ & 4,28 \\
\hline 4 & $\begin{array}{l}\text { Hasil pemeriksaan menunjang } \\
\text { klinik dokter }\end{array}$ & 4,15 \\
\hline 5 & $\begin{array}{l}\text { Evaluasi/kalibrasi alat secara } \\
\text { berkala }\end{array}$ & 3,93 \\
\hline 6 & $\begin{array}{l}\text { Stabilitas sampel terjamin } \\
\text { sesuai dengan kriteria atau } \\
\text { persyaratan tes pemeriksaan }\end{array}$ & 4,17 \\
\hline 7 & $\begin{array}{l}\text { Jenis pemeriksaan di Lab. } \\
\text { Klinik Prodia memiliki } \\
\text { garansi }\end{array}$ & 4,15 \\
\hline 8 & $\begin{array}{l}\text { Jenis pemeriksaan di Lab. } \\
\text { Klinik Prodia dapat dilakukan } \\
\text { dalam berbagai kalangan usia }\end{array}$ & 4,31 \\
\hline
\end{tabular}


Jurnal Manajemen dan Bisnis, Volume 2, No. 2, Januari 2021

\begin{tabular}{|c|c|c|c|c|c|}
\hline 9 & $\begin{array}{l}\text { Lab. Klinik Prodia memiliki } \\
\text { peralatan dan teknologi } \\
\text { terupdate }\end{array}$ & 4,02 & 8 & \multirow{2}{*}{$\begin{array}{l}\text { Petugas layanan Lab. Klinik } \\
\text { Prodia bersikap ramah dan } \\
\text { sopan dalam melayani } \\
\text { pelanggan }\end{array}$} & \multirow[b]{2}{*}{3,96} \\
\hline \multirow[t]{2}{*}{10} & Lab. Klinik Prodia & & & & \\
\hline & $\begin{array}{l}\text { memberikan lembar hasil } \\
\text { pemeriksaan jelas dan } \\
\text { informatif }\end{array}$ & 4,14 & \multirow[t]{2}{*}{9} & \multirow{2}{*}{$\begin{array}{l}\text { Petugas layanan Lab. Klinik } \\
\text { Prodia senantiasa tepat waktu } \\
\text { dalam menyerahkan hasil } \\
\text { pemeriksaan }\end{array}$} & \multirow[t]{2}{*}{3,88} \\
\hline \multicolumn{2}{|r|}{ ta-rata } & 4,18 & & & \\
\hline \multirow{2}{*}{\multicolumn{3}{|c|}{$\begin{array}{l}\text { Dari tabel di atas terlihat nilai } \\
\text { si rata-rata skor dimensi variabel } \\
\text { produksi sober } 4.18\end{array}$}} & 10 & $\begin{array}{l}\text { Kemudahan pelanggan dalam } \\
\text { menghubungi Lab. Klinik } \\
\text { Prodia }\end{array}$ & 3,64 \\
\hline & & & & Rata-rata & 3,98 \\
\hline
\end{tabular}

masuk dalam rentang 3,40-4,19, dan prediksi rata-rata persentase sebesar $83,68 \%$. Niai Dari tabel di atas terlihat nilai $83,68 \%$ masuk dalam rentang $68 \%$ - 83,99prediksi rata-rata skor dimensi variabel $\%$. Hal ini berarti dimensi variabel kualitaspelayanan prima sebesar 3,98. Nilai 3,98 produk dikategorikan baik atau rata-ratamasuk dalam rentang 3,40-4,19, dan prediksi responden menyatakan setuju.

rata-rata persentase sebesar $79,52 \%$. Niai

Di bawah ini dipaparkan masing-79,52\% masuk dalam rentang $68 \%-83,99$ masing indikator dari dimensi kualitas\%. Hal ini berarti dimensi variabel pelayanan produk dengan hasil prediksi rata-rata skor. prima dikategorikan baik atau rata-rata responden menyatakan setuju.

Dimensi Variabel Pelayanan Prima Di bawah ini dipaparkan masing-

\begin{tabular}{|c|c|c|c|c|c|}
\hline No & Pelayanan Prima & Skor & \multirow{2}{*}{\multicolumn{3}{|c|}{$\begin{array}{l}\text { masing indikator dari dimensi kualit } \\
\text { produk dengan hasil prediksi rata-rata skor. } \\
\text { Dimensi Variabel Kepuasan Pelanggan }\end{array}$}} \\
\hline 1 & $\begin{array}{l}\text { Kelengkapan sarana promosi } \\
\text { (brosur, kliping, dll) di area } \\
\text { pelayanan Lab. Klikik Prodia }\end{array}$ & 4,08 & & & \\
\hline \multirow[t]{2}{*}{2} & \multirow{2}{*}{$\begin{array}{l}\text { Sarana dan prasarana ruang } \\
\text { layanan Lab. Klinik Prodia } \\
\text { membuat nyaman }\end{array}$} & \multirow[t]{2}{*}{3,99} & No & Kepuasan Pelanggan & Skor \\
\hline & & & \multirow[t]{2}{*}{1} & $\begin{array}{l}\text { Ketepatan layanan yang } \\
\text { diberikan sesuai dengan }\end{array}$ & 4,13 \\
\hline \multirow[t]{3}{*}{3} & \multirow{3}{*}{$\begin{array}{l}\text { Petugas layanan memiliki } \\
\text { kecepatan dalam melayani } \\
\text { pelanggan }\end{array}$} & & & harapan pelanggan & \\
\hline & & \multirow[b]{2}{*}{4,02} & 2 & Hasil pemeriksaan akurat & 4,21 \\
\hline & & & \multirow[t]{2}{*}{3} & \multirow{2}{*}{$\begin{array}{l}\text { Kepuasan biaya sesuai } \\
\text { dengan benefit yang diterima } \\
\text { pelanggan }\end{array}$} & \multirow[b]{2}{*}{3,94} \\
\hline \multirow[t]{2}{*}{4} & \multirow{2}{*}{$\begin{array}{l}\text { Pengetahuan petugas layanan } \\
\text { dalam memberikan informasi } \\
\text { pemeriksaaan dapat } \\
\text { dimengerti }\end{array}$} & & & & \\
\hline & & 4,07 & \multirow[t]{2}{*}{4} & \multirow{2}{*}{$\begin{array}{l}\text { Apakah anda akan } \\
\text { merekomendasikan kerabat } \\
\text { untuk melakukan } \\
\text { pemeriksaan di Lab. Klinik } \\
\text { Prodia }\end{array}$} & \\
\hline \multirow[t]{2}{*}{5} & \multirow{2}{*}{$\begin{array}{l}\text { Kemampuan petugas layanan } \\
\text { Lab. Klinik Prodia dalam } \\
\text { pengambilan darah satu kali } \\
\text { tusuk }\end{array}$} & \multirow[b]{2}{*}{3,88} & & & 4,05 \\
\hline & & & \multirow[t]{3}{*}{5} & \multirow{3}{*}{$\begin{array}{l}\text { Terjaminnya proses dari } \\
\text { preanalitik sampai dengan } \\
\text { keluar hasil sesuai dengan } \\
\text { standarisasi yang berlaku di } \\
\text { seluruh cabang }\end{array}$} & \multirow[b]{3}{*}{4,05} \\
\hline 6 & $\begin{array}{l}\text { Petugas layanan Lab. Klinik } \\
\text { Prodia menjaga kerahasiaan } \\
\text { hasil dan profile pelanggan }\end{array}$ & 4,14 & & & \\
\hline \multirow[t]{2}{*}{7} & \multirow{2}{*}{$\begin{array}{l}\text { Petugas layanan Lab. Klinik } \\
\text { Prodia berpenampilan } \\
\text { menarik, bersih dan rapi }\end{array}$} & \multirow{3}{*}{4,10} & & & \\
\hline & & & \multirow[t]{2}{*}{6} & \multirow{2}{*}{$\begin{array}{l}\text { Apakah jenis pemeriksaan } \\
\text { sesuai dengan kebutuhan } \\
\text { pelanggan }\end{array}$} & \\
\hline & & & & & \\
\hline
\end{tabular}


Jurnal Manajemen dan Bisnis, Volume 2, No. 2, Januari 2021

\begin{tabular}{|c|l|c|}
\hline 7 & $\begin{array}{l}\text { Keterampilan petugas } \\
\text { layanan menangani keluhan } \\
\text { pelanggan }\end{array}$ & 3,97 \\
\hline 8 & $\begin{array}{l}\text { Layanan di Lab. Klinik } \\
\text { Prodia terhadap pelanggan } \\
\text { baik }\end{array}$ & 4,03 \\
\hline 9 & $\begin{array}{l}\text { Pelanggan dapat merasa } \\
\text { nyaman menggunakan jasa } \\
\text { pemeriksaan }\end{array}$ & 4,11 \\
\hline 10 & $\begin{array}{l}\text { Kemampuan petugas dalam } \\
\text { memberikan informasi } \\
\text { layanan }\end{array}$ & 4,00 \\
\hline \multicolumn{1}{|c|}{ Rata-rata } & $\mathbf{4 , 0 6}$ \\
\hline
\end{tabular}

Dari tabel 4.7 di atas terlihat nilai prediksi rata-rata skor dimensi variabel kepuasan Pelanggan sebesar 4,06. Nilai 4,06 masuk dalam rentang 3,40-4,19, dan prediksi rata-rata persentase sebesar $81,28 \%$. Niai $81,28 \%$ masuk dalam rentang $68 \%$ $83,99 \%$ Hal ini berarti dimensi variabel pelayanan prima dikategorikan baik atau rata-rata responden menyatakan setuju.

Hasil uji validitas setiap instrumen butir pernyataan seluruhnya diperoleh nilai $r$ hitung > $\mathrm{r}$ tabel, sehingga dinyatakan valid. Tingkat reliabilitasnya juga cukup tinggi yakni senilai antara 0,8 sampai dengan 0,9. persyaratan normalitas data juga terpenuhi, termasuk atas uji heteroskedastisitas maupun uji multikolonieritas.

Pada bagian ini akan digambarkan hasil uji hipotesis yang telah diolah oleh Statistical Product and Service Solutions (SPSS) versi 24.0 dalam bentuk tabel.
Uji $\mathrm{t}$ bertujuan untuk menguji pengaruh masing-masing variabel independent (Kualitas Produk dan Pelayanan Prima) terhadap variabel dependen (Kepuasan Pelanggan). Hasil uji analisis regresi linear coefficients dengan menggunakan Statistical Product and Service Solutions (SPSS) versi 24.0 terlihat pada tabel diatas:

a. Uji t untuk Variabel Kualitas Produk Nilai $\mathrm{t}$ hitung dari hasil pengelolahan SPSS $=2,012$ dan nilai probabilitas $=$ 0,047 . Nilai $t$ hitung $>t$ tabel atau 2,012 > 1,98447 dan nilai signifikasi $<0,05$ atau $0,047<0,05$ maka ada pengaruh kualitas produk terhadap kepuasan Pelanggan secara signifikan.

b. Uji t untuk Variabel Pelayanan Prima

Nilai $\mathrm{t}$ hitung dari hasil pengelolahan SPSS $=10,124$ dan nilai probabilitas $=$ 0,00 . Nilai t hitung $>\mathrm{t}$ tabel atau 10,124

$>1,98447$ dan nilai signifikasi $<0,05$ atau $0,00<0,05$ maka ada pengaruh pelayanan prima terhadap kepuasan Pelanggan secara signifikan.

Hasil Uji Simultan dengan uji $F$ atas variabel kualitas produk dan pelayanan prima terhadap variabel kepuasan pelanggan, terlihat pada tabel sebagai berikut ini

\section{Hasil Uji Simultan (Uji F)} ANOVA $^{a}$

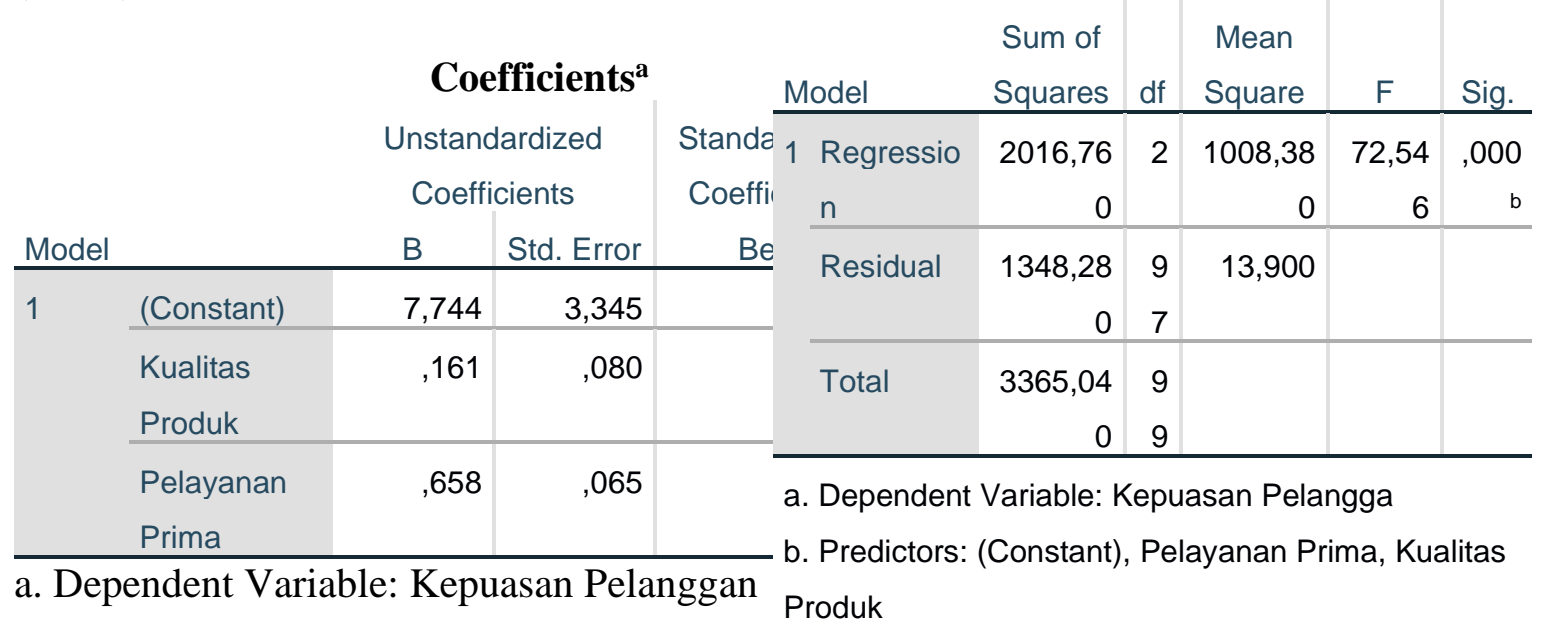


Nilai $F$ hitung dari hasil pengelolahan SPSS $=72,546$ dan nilai probabilitas $=0,00$. Nilai $\mathrm{F}$ hitung $>\mathrm{F}$ tabel atau 72,546 $>3,09$ dan nilai signifikasi $<0,05$ atau $0,00<0,05$ maka ada pengaruh kualitas produk dan pelayanan prima secara simultan terhadap kepuasan Pelanggan.

Terlihat dalam kurva distribusi uji $\mathrm{F}$ di atas nilai $\mathrm{Fh}>$ nilai $\mathrm{F}$ tabel atau 72,546 > 3,09 berada dalam daerah penolakan Ho berarti terdapat pengaruh kualitas produk dan pelayanan prima secara simultan sangat signifikan terhadap kepuasan Pelanggan .

Adapun koefisien determinasi atau nilai besarnya pengaruh kualitas produk dan pelayanan prima terhadap kepuasan pelanggan adalah sebagai berikut:

\section{Hasil Koefisien Determinasi}

\begin{tabular}{|c|c|c|c|c|}
\hline \multicolumn{5}{|c|}{ Model Summaryb } \\
\hline Model & $\mathrm{R}$ & $\begin{array}{c}\mathrm{R} \\
\text { Square }\end{array}$ & $\begin{array}{c}\text { Adjusted R } \\
\text { Square }\end{array}$ & $\begin{array}{c}\text { Std. Error of } \\
\text { the } \\
\text { Estimate }\end{array}$ \\
\hline 1 &, $774^{a}$ & ,599 & ,591 & 3,728 \\
\hline
\end{tabular}

a. Predictors: (Constant), Pelayanan Prima, Kualitas Produk

b. Dependent Variable: Kepuasan Pelangga

Berdasarkan tabel atas koefisien determinasi (KD) adalah

$R$ Square. Nilai $R$ Square $\left(\mathrm{R}^{2}\right)=0,599$ adalah sebagai koefisien determinasi $=59,90$ $\%$, berarti sebesar 59,90\% kontribusi atau pengaruh variabel Kualitas Produk (X1) dan Pelayanan Prima $\left(\mathrm{X}_{2}\right)$. secara simultan (bersama-sama) terhadap variabel Kepuasan Pelanggan (Y), sedangkan sisanya sebesar $40,10 \%$ adalah pengaruh faktor lainnya yang tidak diteliti.

\section{KESIMPULAN}

Dari analisis yang telah dilakukan dalam penelitian ini, dapat disimpulkan sebagai berikut:

a. Terdapat pengaruh kualitas produk terhadap kepuasan pelanggan lab. klinik Prodia, hal ini dibuktikan dan hasil penelitian nilai $\mathrm{t}$ hitung $>\mathrm{t}$ tabel atau 2,012>1,98447 berarti ada pengaruh kualitas produk terhadap kepuasan pelanggan. Dan nilai $t$ signifikasi $<0,05$ atau $0,047<0,05$ berarti ada pengaruh kualitas produk terhadap kepuasan pelanggan. Berarti hubungan variabel kualitas produk dengan variabel kepuasan pelanggan dikategortikan cukup signifikan.

b. Terdapat pengaruh pelayanan prima terhadap kepuasan pelanggan lab. klinik Prodia, hal ini dibuktikan dan hasil penelitian nilai $\mathrm{t}$ hitung $>\mathrm{t}$ tabel atau $10,124>1,98447$ berarti ada pengaruh pelayanan prima terhadap kepuasan pelanggan, nilai signifikasi $<0,05$ atau $0,00<0,05$ berarti ada pengaruh pelayanan prima terhadap kepuasan pelanggan. Hal ini berarti hubungan variabel pelayanan prima dengan variabel kepuasan pelanggan dikategortikan erat.

. Terdapat pengaruh kualitas produk, dan layanan prima secara bersama-sama terhadap kepuasan pelanggan lab. klinik Prodia hal ini dibuktikan dan hasil penelitian nilai $\mathrm{F}$ hitung $\mathrm{F}$ hitung $>\mathrm{F}$ tabel atau 72,546 > 3,09 berarti ada pengaruh kualitas produk dan pelayanan prima secara simultan terhadap kepuasan pelanggan, nilai signifikasi $<0,05$ atau $0,00<0,05$ berarti ada pengaruh kualitas produk dan pelayanan prima secara simultan terhadap kepuasan pelanggan. Adapun nilai koefisien determinasi (KD) adalah $R$ Square $=0,599$, berarti sebesar 59,90 $\%$ kontribusi atau pengaruh variabel Kualitas Produk (X1) dan Pelayanan Prima $\left(\mathrm{X}_{2}\right)$ secara simultan (bersamasama) berpengaruh terhadap Kepuasan Pelangga (Y), sedangkan sisanya sebesar 40,10 \% adalah pengaruh faktor lainnya yang tidak diteliti. 
Jurnal Manajemen dan Bisnis, Volume 2, No. 2, Januari 2021

DAFTAR PUSTAKA

Abdurrahman,
Nana Herdiana. 2015. Manajemen

Strategi

Pemasaran.

Bandung: Pustaka Setia.

Ancellawati. 2013. Manajemen

Pemasaran Indonesia. Jakarta:

Salemba Empat.

Assauri, Sofjan. 2014. Manajemen

Pemasaran, Dasar, Konsep dan

Strategi. Jakarta: Rajawali Press.

Assauri, Sofjan 2015. Manajemen

Pemasaran. Jakarta: Rajawali Pers.

Barata, Atep Adya. 2017. Dasar-Dasar

Pelayanan Prima. Jakarta: PT Elex

Media Komputindo.

Boediwarsono. 2015. Layanan Sepenuh Hati.

Surabaya: Prodia.

Daryanto. 2015. Konsumen dan

Pelayanan Prima. Yogyakarta: Gava

Media.

Engel, J. F. 2014. Perilaku Konsumen.

Jakarta: Binarupa Aksara.

Hasibuan, Malayu S.P. 2014. Dasar-

Dasar Perbankan. Jakarta: PT

Aksara.

Hendra, Teguh. 2013. Manajemen

Pemasaran. Jakarta: Salemba Empat.

Hurriyati, Ratih. 2011. Bauran

Pemasaran dan

Kasmir. 2017. Customer Services

Excellent: Teori dan Praktik.

Jakarta: Rajawali Pers.

Kotler, Philip dan Amstrong G. 2012.

Prinsip-Prinsip Pemasaran. Jakarta:

Erlangga.

Kotler, Philip dan Amstrong G. 2013.

Prinsip-Prinsip Pemasaran

(Terjemahan: Damos Sihombing dan

Wisnu Chandra K.). Jakarta: Erlangga.

Kotler, Philip dan Amstrong G. 2013.

Prinsip-Prinsip Pemasaran (Ahli

Bahasa: Dwianoegrahwati

Setyoningsih, Indra Almahdy). Jakarta:

Erlangga.

Kotler, Philip dan Keller, K. L. 2013. Manajemen Pemasaran. (Ahli
Bahasa: Benyamin Molan). Edisi

Kedua Belas Jilid 1. Jakarta: PT

Indeks.

Lamb, Charles. W. 2012. Pemasaran. Buku

I Edisi Pertama. Jakarta: Salemba

Empat.

Lupiyoadi, Rambat. 2012. Manajemen

Pemasaran. Jakarta: Salemba

Empat.

Lupiyoadi, Rambat. 2013. Manajemen

Pemasaran Jasa Berbasis Kompetensi.

Edisi 3. Jakarta: Salemba.

Mukarom, Zaenal. 2015. Manajemen Pelayanan Publik. Bandung:

Pustaka Setia.

Mullins, J. W. et al. 2013. Marketing Strategy. New York: The McGrawHill.

M. Nur, Rianto, Al Arif. 2014.

Dasar-Dasar Pemasaran

Bank Syariah. Bandung:

Altabeta.

Nitisusantro, Mulyadi. 2013. Perilaku

Konsumen. Bandung: Alfabeta.

Rahman, Arif. 2015. Strategi Dahsyat Marketing Mix For Small Business:

Cara Jitu Merontokkan Pesaing. Jakarta: TransMedia.

Rahmayanty, Nina. 2013. Manajemen Pelayanan Prima. Yogyakarta: Graha

Loyalltas. Konsumen. Bandung: Alfabeta.

Rangkuti, F. 2016. Customer Care Excellence Meningkatkan Kinerja Perusahaan Melalui Pelayanan Prima. Jakarta: Gramedia Pustaka Utama.

Sangadji dan Sopiah. 2013. Consumer Behavior: Perilaku Konsumen dan

Strategi Pemasaran Jilid 2. Jakarta: Erlangga.

Setyobudi, Daryanto Ismanto. 2015. Konsumen dan Pelayanan Prima. Yogyakarta: Gava Media.

Silaen, Sofar. 2018. Metodologi Penelitian Sosial untuk Penulisan Skripsi dan Tesis. Jakarta: In Media.

Silaen, Sofar. 2018. Penerapan Bahasa Indonesia yang Benar dan 
Jurnal Manajemen dan Bisnis, Volume 2, No. 2, Januari 2021

Pengolahan Data dengan SPSS untuk Suryana. 2013. Kewirausahaan Kiat dan

Penulisan Skripsi. Jakarta: In Media

Sugiyono. 2017. Metode Penelitian

Poses Menuju Sukses. Jakarta: Salemba Empat.

Kombinasi Mixed Methods. Bandung: Tjiptono, Fandy. 2012. Service Management Alfabeta.

Sunyoto, Danang. 2012. Konsep Dasar Mewujudkan Layanan Prima. Yogyakarta: Andi Offset.

Riset Pemasaran dan Perilaku Konsumen. Yogyakarta: Caps.

Sunyoto, Danang. 2012. Dasar-Dasar

Manajemen Pemasaran. Yogyakarta: PT Buku Seru.

Sunyoto, Danang. 2013. Teori Kuesioner dan Analisis Data untuk Pemasaran dan Perilaku Konsumen. Yogyakarta: Graha Ilmu.

Tjiptono, Fandy. 2014. Manajemen Jasa. Yogyakarta: Andi Offset.

Tjiptono, Fandy. 2014. Strategi Pemasaran. Yogyakarta: Andi Offset.

Vliet, V. V. 2011. Service Marketing Mix $7 P^{\prime}$ 's. Retrieved [insert date] from ToolsHero: https://www.toolshero.com/marketin g/service-market-ing -mix-7ps/.

Yamit. 2013. Manajemen Kualitas Produk dan Jasa. Yogyakarta: Ekonisia. 